\title{
Bandwidth Enhancement of a Backfire Microstrip Patch Antenna for Pervasive Communication
}

\author{
Puran Gour ${ }^{1}$ and Ravishankar Mishra ${ }^{2}$ \\ ${ }^{1}$ NRI Institute of Information Science and Technology, Bhopal 462021, India \\ ${ }^{2}$ Sagar Institute of Science and Technology, Bhopal 462036, India \\ Correspondence should be addressed to Puran Gour; er.purangour@gmail.com
}

Received 5 August 2013; Revised 19 May 2014; Accepted 28 May 2014; Published 30 June 2014

Academic Editor: Atsushi Mase

Copyright (C) 2014 P. Gour and R. Mishra. This is an open access article distributed under the Creative Commons Attribution License, which permits unrestricted use, distribution, and reproduction in any medium, provided the original work is properly cited.

Backfire antenna $0.265 \lambda$ for bandwidth enhancement is proposed and investigated. The proposed antenna is fed by a $50 \Omega$ coaxial feed. The bandwidth of proposed antenna for $\mathrm{S}$ and $\mathrm{C}$ band is investigated. The performance of backfire antenna is investigated by performing numerical calculation by using various mathematical formulas to determine necessary dimensions of the antenna and simulation by using commercially available Method of Moments software. Here we design proposed geometry for $3 \mathrm{GHz}$. For this geometry we achieved $52.8 \%$ bandwidth for VSWR $<2$, minimum return loss $-20 \mathrm{~dB}$, and maximum directivity $7.2 \mathrm{dBi}$.

\section{Introduction}

With the development of pervasive communication, bandwidth enhancement becomes a necessary component. This is one of the important elements in the RF system for receiving and transmitting the radio wave signals from and into the air as the medium. Without proper design of the antenna, the signal generated by the RF system will not be transmitted and no signal can be detected at the receiver. Many types of antenna have been designed to cater for variable application and to be suitable for their needs. The backfire antenna was initially described in 1960 by H. W. Ehernspeck and much simplified version, called the short backfire antenna, has been subjected to extensive experimental studies [1]. The short back fire antenna consists of large reflector $2 \lambda$ in diameter with a rim of height $0.25 \lambda$ and a small reflector $0.4 \lambda$ in diameter separated by approximately $0.5 \lambda$. The antenna behaves like an open cavity resonator. A short backfire antenna is a type of a directional antenna characterized by high gain, relatively small size, and narrow band $[2,3]$. The feed location in the backfire antenna constructed upon the antenna characteristics is also examined. Several attempts have been made to enhance the bandwidth performance of the common dipole-fed backfire by employing various other feeding mechanisms with moderate success. The microstrip patch-excited short backfire antenna is superior to these other designs in its reduced size and mass while maintaining comparable performance [4]. H. W. Ehernspeck has designed a backfire antenna which is constructed by placing of a big reflector at the open end of an endfire antenna perpendicularly to its axis. The geometry of the backfire antenna is shown in Figure 1. It consists of a source $F$, surface wave structure $S$ and two parallel disk reflectors: small reflector $R_{1}$ and big reflector $R_{2}$ which reflects the surface wave $S W_{2}$ toward the small reflector $R_{1}$, where it is radiated from the antenna aperture $V V^{\prime}$ into the space. Thus, the radiation of the antenna is directed in inverse direction in comparison with the radiation of the ordinary endfire antenna used as a backfire antenna prototype. Because of this reason it is called backfire antenna [1].

\section{Feeding Techniques}

There are four feeding techniques that can be used while designing the backfire antenna. These techniques are coaxial probe/probe coupling, microstrip feed, proximity (electromagnetically) coupled microstrip antenna, and aperture coupled microstrip antenna feed. The comparison between these techniques is shown in Table 1. 
TABle 1: Comparison of different feeding methods.

\begin{tabular}{lcccc}
\hline Characteristics & Line feed & Coaxial feed & Aperture coupled & Proximity coupled \\
\hline Configuration & Coplanar & Nonplanar & Planar & Planar \\
Spurious feed radiation & More & More & More & More \\
Polarization purity & Good & Good & Poor & Poor \\
Ease of fabrication & Easy & Soldering and drilling & Good & Poor \\
Reliability & Better & Poor due to soldering & Easy & Good \\
Impedance matching & Easy & Easy & $2-5 \%$ & Easy \\
Bandwidth & $2-5 \%$ & $2-5 \%$ & $13 \%$ \\
\hline
\end{tabular}

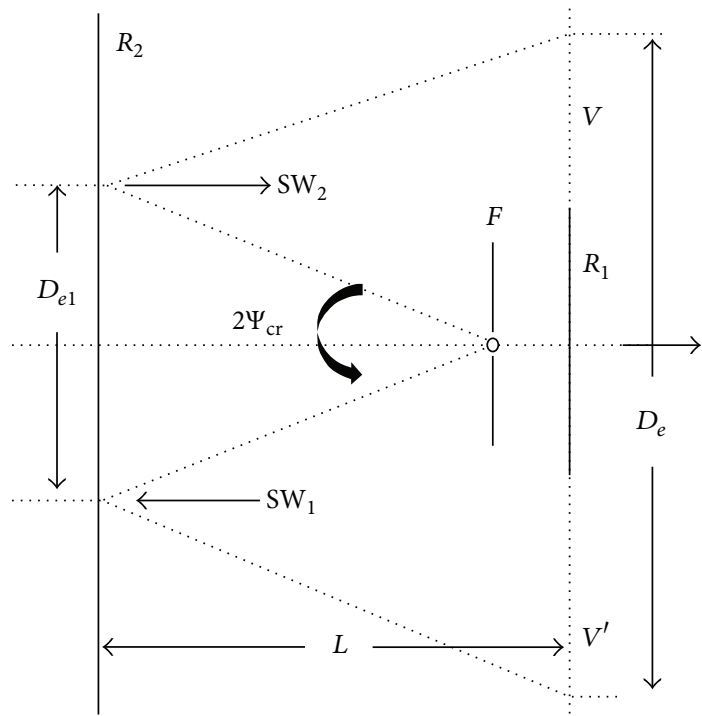

FIgURE 1: Basic geometry of back fire antenna [1].

From the mentioned techniques in Table 1 we choose coaxial feed to feed the proposed antenna. This technique allows independent optimization of the feed and radiating parts of the antenna due to the metal ground plane placed between them.

\section{Designing of Backfire Antenna}

For the designing of any backfire antenna we can use mainly two parts.

(i) Mathematical analysis.

(a) For the designing of short backfire antenna (SBFA) first we have to choose the substrate of the antenna.

(b) For numerical analysis various formulas are used.

(c) And lastly for input purpose different feeding methods are used; in this we used coaxial feed line technique.

(ii) Antenna design by using IE3D software.

(a) For simulation part different types of software are used, we used IE3D software.

(b) Different steps are followed for the designing of SBFA antenna.
TABLE 2: Data sheet of different substrates.

\begin{tabular}{lccc}
\hline Properties & LTCC & FR4 Epoxy & RT Duroid \\
\hline Dielectric constant & 7.4 & 4.36 & 2.2 \\
Loss tangent & 0.023 & 0.019 & 0.0004 \\
Breakdown voltage & $20-28 \mathrm{kv}$ & $55 \mathrm{kv}$ & $>60 \mathrm{kv}$ \\
\hline
\end{tabular}

3.1. Mathematical Analysis. Mathematical analysis is necessary for knowing the exact dimension of the patch to be designed. By performing mathematical analysis we calculate width and length of the patch, ground plane, and reflectors. For mathematical purpose the main important point is how we can choose substrate. The bandwidth of the short backfire antenna is directly proportional to the substrate thickness (h). The bandwidth of the short backfire antenna is inversely proportional to the square root of substrate dielectric constant $\left(\varepsilon_{r}\right)$. Substrate thickness is another important design parameter. Thickness of the substrate increases the fringing field at the patch periphery like low dielectric constant and thus increases the radiated power. It also gives lower quality factor and so higher bandwidth. The low value of dielectric constant increases the fringing field at the patch periphery and thus increases the radiated power. A small value of loss tangent is always preferable in order to reduce dielectric loss and surface wave losses which increases the efficiency of the antenna [2].

There are three essential parameters that should be known while performing mathematical analysis.

(i) Frequency of operation $\left(f_{0}\right)$ : the resonant frequency of the antenna must be selected appropriately.

(ii) Dielectric constant of the substrate $\left(\varepsilon_{r}\right)$ : the dielectric material selected for our design for microstrip patch and ground plane is FR4 which has a dielectric constant of 4.3 (Table 2). Also an effective dielectric constant $\left(\varepsilon_{\text {eff }}\right)$ must be obtained in order to account for the fringing and the wave propagation in the line.

(iii) Height of dielectric substrate $(h)$ : the height of the dielectric substrate is selected as $1.5 \mathrm{~mm}$.

Formulae used for mathematical calculations are

$$
\begin{gathered}
W=\frac{c}{2 f \sqrt{\left(\varepsilon_{r}+1\right) / 2}} \\
\varepsilon_{r \text { eff }}=\left(\frac{\varepsilon_{r}+1}{2}\right)+\left(\frac{\varepsilon_{r}-1}{2}\right)\left[1+12 \frac{h}{W}\right]^{-1 / 2},
\end{gathered}
$$




$$
\begin{gathered}
\Delta L=0.412 h \frac{\left(\varepsilon_{r e f f}+0.3\right)((W / h)+0.264)}{\left(\varepsilon_{r e f f}+0.258\right)((W / h)+0.8)}, \\
L=\frac{c}{2 f \sqrt{\varepsilon_{r e f f}}}-2 \Delta L, \\
L_{0}=L+6 h, \\
W_{0}=W+6 h,
\end{gathered}
$$

where $f$ = operating frequency, $\varepsilon_{r}=$ permittivity of the dielectric, $\varepsilon_{\text {reff }}=$ effective permittivity of the dielectric, $W=$ patch's width, $L=$ patch's length, $h=$ thickness of the dielectric, $L_{0}=$ length of ground plate, and $W_{0}=$ width of ground plate.

3.2. Effect of Substrate. While performing mathematical analysis effect of substrate is also considered. Some of the important points that needed to be considered are as follows [5-8].

(i) The bandwidth of microstrip patch antenna is directly proportional to the substrate thickness $(h)$ and inversely proportional to the square root of substrate dielectric constant $(\varepsilon)$.

(ii) Thick substrate increases the fringing field at the patch periphery and thus increases the radiated power.

(iii) A small value of loss tangent is always preferable in order to reduce dielectric loss and surface wave loss and it increases the efficiency of antenna.

(iv) Low dielectric constant is used which has very low water absorption capability.

3.3. Antenna Design by Using IE3D Software. The proposed antenna is designed in Flame Retardant 4 (FR4) such that the return loss, directivity, and the radiation pattern can be obtained by using the EM Simulator IE3D (version 9.0) software. Based on the simulations and mathematical calculation we find the length and width of rectangular microstrip patch of short backfire antenna, which is calculated as shown in Tables 3 and 4.

\section{Simulation and Results}

The antenna was simulated by IE3D software, which uses the Method of Moments approach in its modeling equations with the final patch obtained shown in Figure 2.

The antenna geometry consist of two reflector one rectangular and other circular and between them patch is connected (Figures 3 and 4 ). The 3D view of the proposed antenna is as shown in Figure 5.

The obtained minimum value of the antenna return loss is $-20 \mathrm{~dB}$ at the frequency of $5.5 \mathrm{GHz}$ as shown in Figure 6. Thus, the bandwidth obtained from the return loss result is $52.8 \%$.

Moreover, VSWR is a measure of how well matched is the antenna to the cable impedance. A proposed antenna would have a VSWR of less than 2 for 4.5-7.9 GHz. This indicates less power is reflected back from source. VSWR obtained from the simulation is less than 2 which is approximately equal to

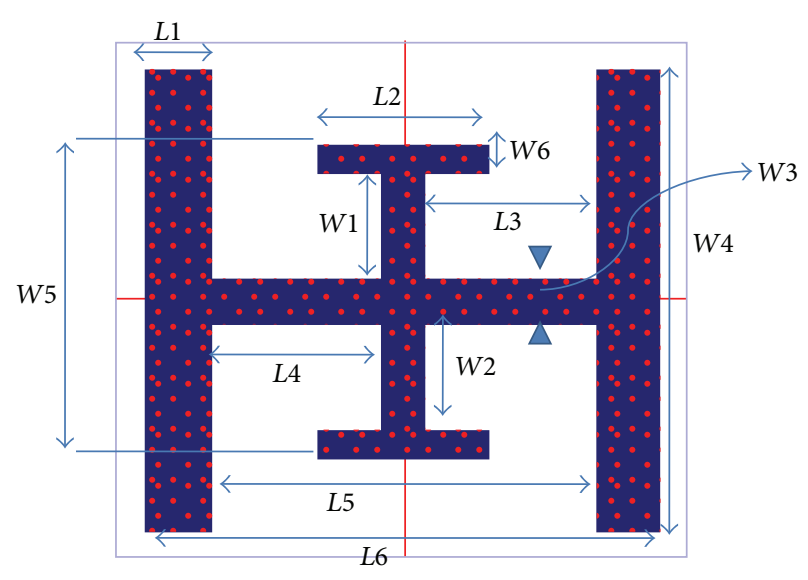

Figure 2: Proposed excitation structure where the feed is to be given.

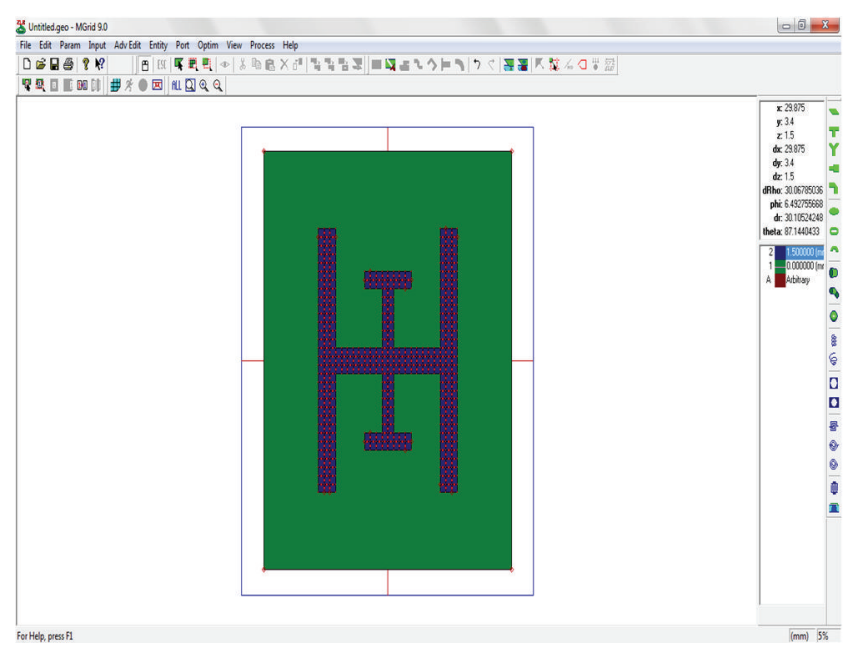

FIGURE 3: Geometry of proposed antenna with main rectangular reflector.

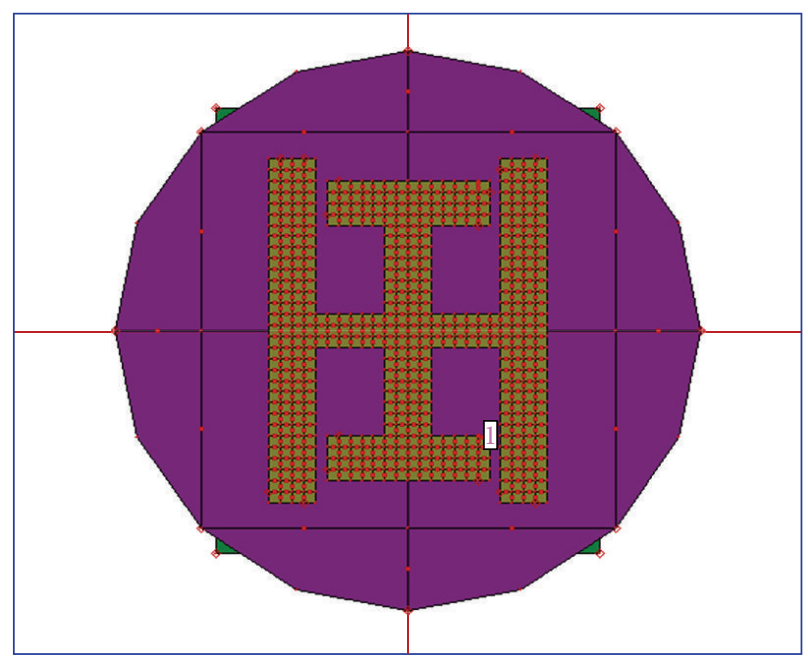

FIGURE 4: Geometry of proposed antenna. 
TABLE 3: Mathematical calculation for the proposed antenna.

\begin{tabular}{lcc}
\hline $\begin{array}{l}\text { Serial } \\
\text { number }\end{array}$ & Parameters & $\begin{array}{c}\text { Values for } \\
\text { proposed antenna }\end{array}$ \\
\hline 1 & Design frequency $\left(f_{0}\right)$ & $3 \mathrm{GHz}$ \\
2 & Dielectric constant $\left(\varepsilon_{r}\right)$ & 4.3 \\
3 & Height of substrate $(h)$ & $1.5 \mathrm{~mm}$ \\
4 & Loss tangent of FR4 & 0.019 \\
5 & Width of rectangular patch $(W)$ & $30.7148 \mathrm{~mm}$ \\
6 & Length of rectangular patch $(L)$ & $23.7388 \mathrm{~mm}$ \\
7 & Width of ground plane $\left(W_{0}\right)$ & $39.7148 \mathrm{~mm}$ \\
8 & Length of ground plane $\left(L_{0}\right)$ & $32.7388 \mathrm{~mm}$ \\
9 & Diameter of big reflector $(d)$ & $50 \mathrm{~mm}$ \\
10 & Height of big reflector $\left(H_{r}\right)$ & $25 \mathrm{~mm}$ \\
& Feed location: & $X_{f}=6.975$ \\
11 & $X_{f}$ (along length) & $Y_{f}=-10.4$ \\
& $Y_{f}$ (along width) & $26.5 \mathrm{~mm}$ \\
\hline
\end{tabular}

TABLE 4: Optimal parameter values of the antenna.

\begin{tabular}{lcc}
\hline Serial number & Parameters & Values of proposed geometry $(\mathrm{mm})$ \\
\hline 1 & Length $L 1$ & $1.4\left(0.014 \lambda_{0}\right)$ \\
2 & Length $L 2$ & $4\left(0.04 \lambda_{0}\right)$ \\
3 & Length $L 3$ & $4\left(0.04 \lambda_{0}\right)$ \\
4 & Length $L 4$ & $4\left(0.04 \lambda_{0}\right)$ \\
5 & Length $L 5$ & $9\left(0.09 \lambda_{0}\right)$ \\
6 & Length $L 6$ & $12\left(0.12 \lambda_{0}\right)$ \\
7 & Width $W 1$ & $3.5\left(0.035 \lambda_{0}\right)$ \\
8 & Width $W 2$ & $3.5\left(0.035 \lambda_{0}\right)$ \\
9 & Width $W 3$ & $1.5\left(0.015 \lambda_{0}\right)$ \\
10 & Width $W 4$ & $15.5\left(0.155 \lambda_{0}\right)$ \\
11 & Width $W 5$ & $10.5\left(0.105 \lambda_{0}\right)$ \\
12 & Width $W 6$ & $1\left(0.01 \lambda_{0}\right)$ \\
\hline
\end{tabular}

1.1:1 as shown in Figure 7. This is considered a good value as the level of mismatch is not very high because high VSWR implies that the port is not properly matched.

The maximum directivity of proposed antenna is $7.2 \mathrm{dBi}$ at $7.5 \mathrm{GHz}$ (Figure 8).

The maximum gain of proposed antenna is $6 \mathrm{dBi}$ at $7.5 \mathrm{GHz}$ (Figure 9).

The $3 \mathrm{D}$ radiation pattern of the antenna at frequency $3.35 \mathrm{GHz}$ (out of antenna frequency bandwidth) is shown in Figures 10 and 11. It can be observed from this radiation that the design antenna has stable radiation pattern throughout the whole operating band.

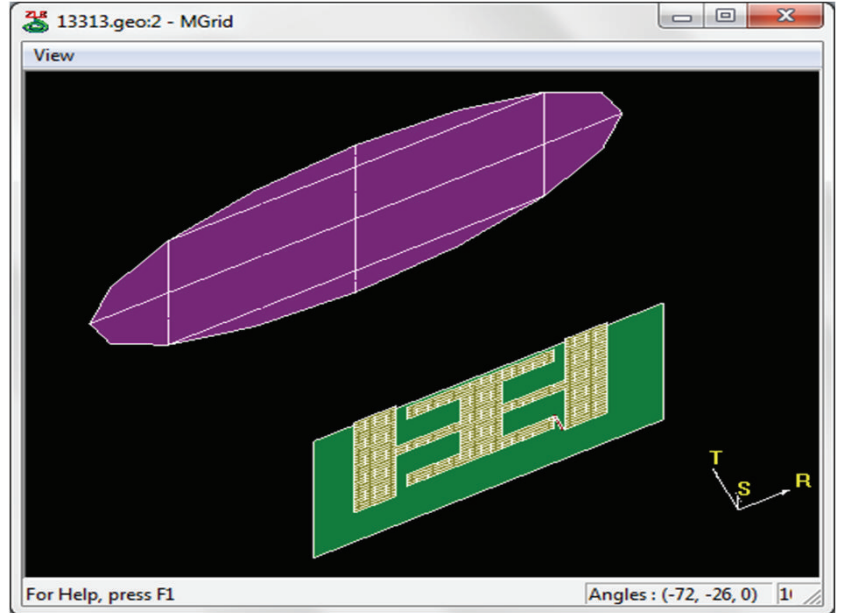

FIGURE 5: 3D view of proposed antenna.

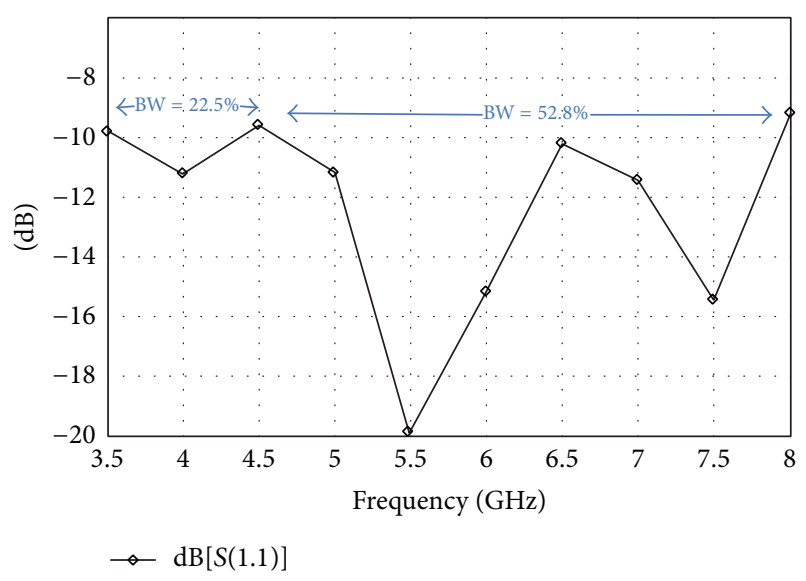

FIGURE 6: Return loss for proposed antenna.

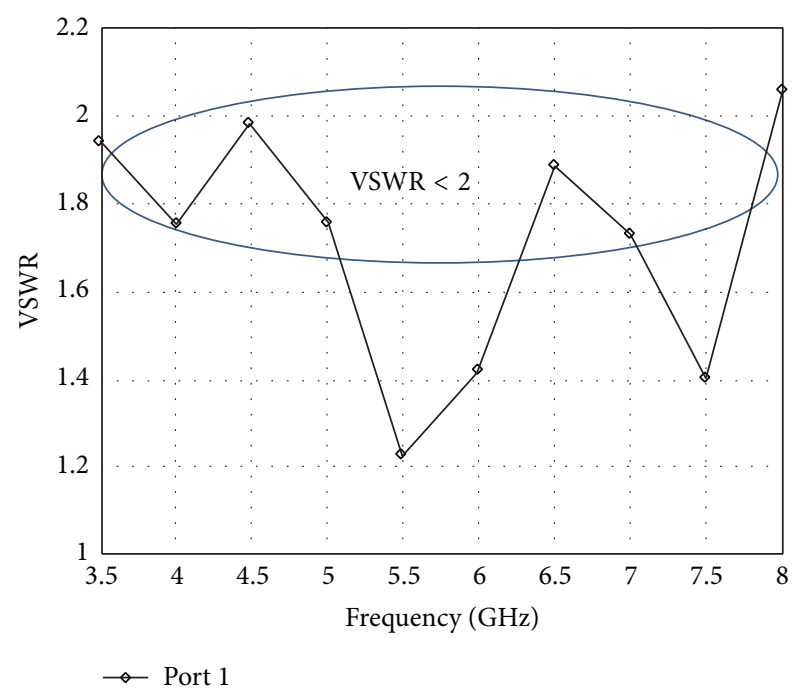

FIGURE 7: VSWR curve for proposed antenna. 
TABLE 5: Basic electrical characteristics of the proposed antenna.

\begin{tabular}{lcc}
\hline Serial number & Parameters & Value \\
\hline 1 & Minimum $S_{11}$ & $-20 \mathrm{~dB}$ at $5.5 \mathrm{GHz}$ \\
2 & Bandwidth & $52.8 \%$ between $(4.6-7.9) \mathrm{GHz}$ \\
3 & VSWR & $<2.0 \mathrm{between}(4.6-7.9) \mathrm{GHz}$ \\
4 & Maximum directivity & $7.2 \mathrm{dBi}$ at $7.5 \mathrm{GHz}$ \\
5 & Maximum gain & $6 \mathrm{dBi}$ at $7.5 \mathrm{GHz}$ \\
6 & Center frequency $f_{0}=0.5\left(f_{\min }+f_{\max }\right)$ & $6.25 \mathrm{GHz}$ \\
\hline
\end{tabular}

TABLE 6: Comparison between the classic SBFA and the proposed antenna.

\begin{tabular}{|c|c|c|c|}
\hline \multirow{2}{*}{ Serial number } & \multirow{2}{*}{ Dimension/parameter } & \multicolumn{2}{|c|}{ Antenna } \\
\hline & & Classic SBFA & Proposed antenna \\
\hline 1 & Center wavelength & $\lambda_{0}$ & $48 \mathrm{~mm}$ \\
\hline 2 & Big reflector diameter $D 2$ & $2 \lambda_{0}$ & $50 \mathrm{~mm}\left(1.04 \lambda_{0}\right)$ \\
\hline 3 & Small rectangular dimension $D 1$ & $0.443 \lambda_{0}$ & $36.227 \mathrm{~mm}\left(0.755 \lambda_{0}\right)$ \\
\hline 4 & Length of the antenna $L_{A}$ & $0.5 \lambda_{0}$ & $26.5 \mathrm{~mm}\left(0.522 \lambda_{0}\right)$ \\
\hline 5 & Distance source, small reflector $d 1$ & $0.25 \lambda_{0}$ & $1.5 \mathrm{~mm}\left(0.031 \lambda_{0}\right)$ \\
\hline 6 & Distance source, big reflector $d 2$ & $0.25 \lambda_{0}$ & $25 \mathrm{~mm}\left(0.521 \lambda_{0}\right)$ \\
\hline 7 & Maximum gain $G$ & $13 \mathrm{dBi}$ & $6 \mathrm{dBi}$ \\
\hline 8 & Bandwidth bw & $4-5 \%$ & $52.8 \%$ \\
\hline
\end{tabular}

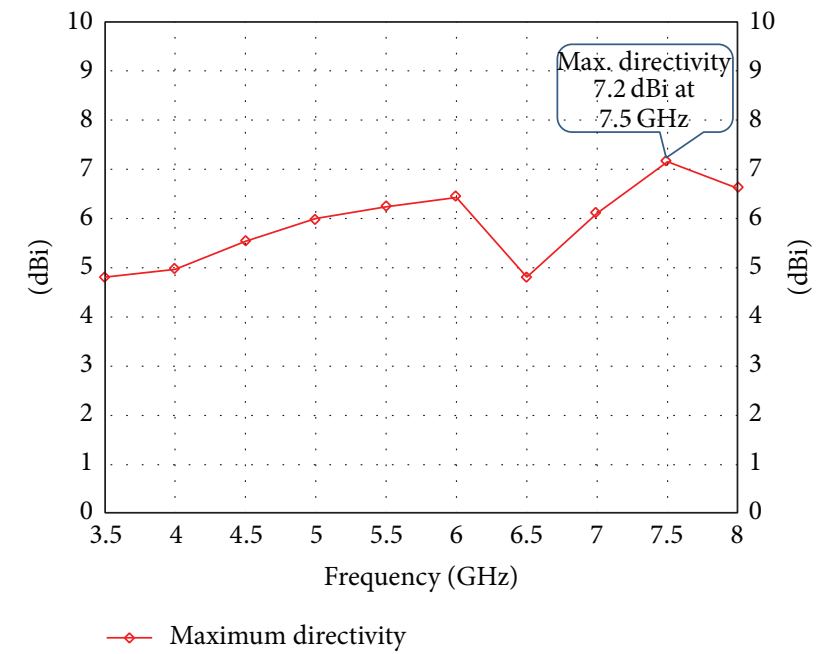

FIGURE 8: Directivity versus frequency curve for proposed antenna.

\section{Validation}

To ensure our graphically simulated results are reliable, we have also validated our results with experimental results obtained from other source reported by Asad et al. [4]. It is evident from [4] that the VSWR bandwidth is $21.28 \%$ in simulation with the finite element method based software tool and $52.8 \%$ at the 4.6 to $7.9 \mathrm{GHz}$ of the reported simulation result. Thus, it has depicted that the VSWR bandwidth spans more in simulated results as compared to reported results. The antenna is validated by using Agilent Network Analyzer N9923A whose hardware result is approximately the same as simulation results as shown in Figures 12, 13, and 14.

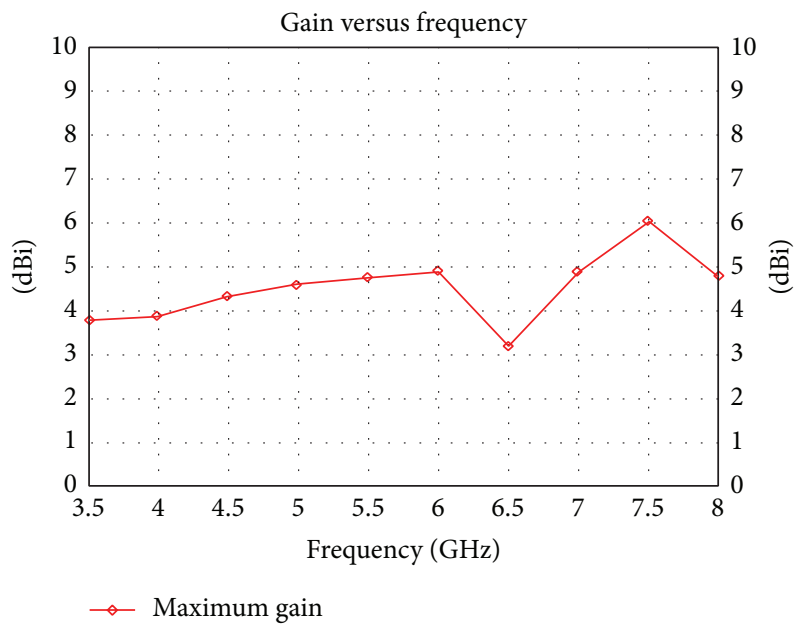

FIGURE 9: Gain curve for proposed antenna.

The basic electrical characteristics of the proposed antenna are summarized in Table 5 .

A comparison between the dimension and some electrical characteristics of the classic SBFA with optimum dimension and the proposed antenna is accomplished in Table 6 .

It is seen from Tables 3, 5, and 6 that the used nonoptimum (smaller) dimension of the big reflector and nonoptimum place of the source (feed) in the proposed antenna shifts the center frequency 2 times from the design frequency (from $3 \mathrm{GHz}$ to $6.25 \mathrm{GHz}$ ) and decreases five times (with $7 \mathrm{~dB}$ ) its gain, but the wideband microstrip excitation leads to a dramatic increase of the antenna bandwidth, approximately 12 times (from $4.5 \%$ to $52.8 \%$ ) 


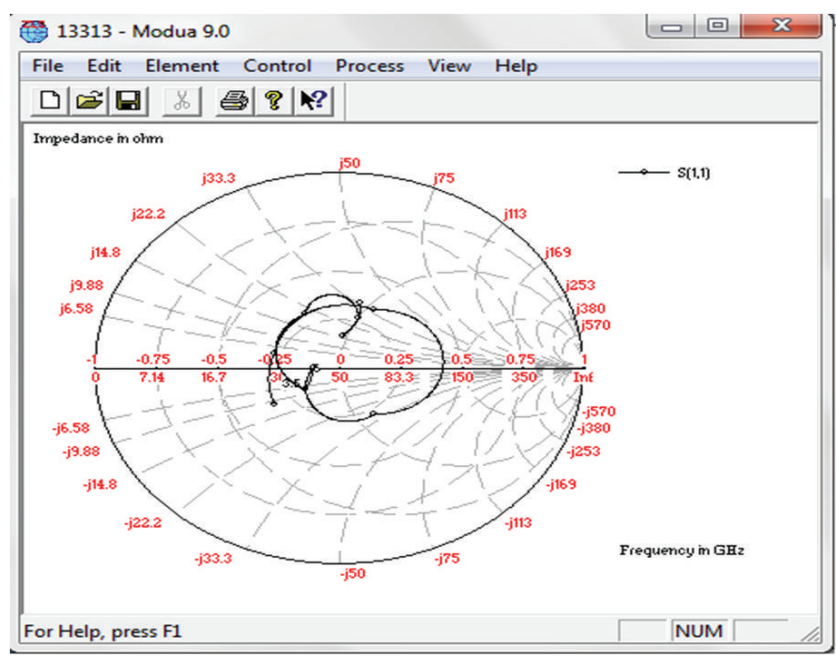

FIgURE 10: Smith chart for proposed antenna.

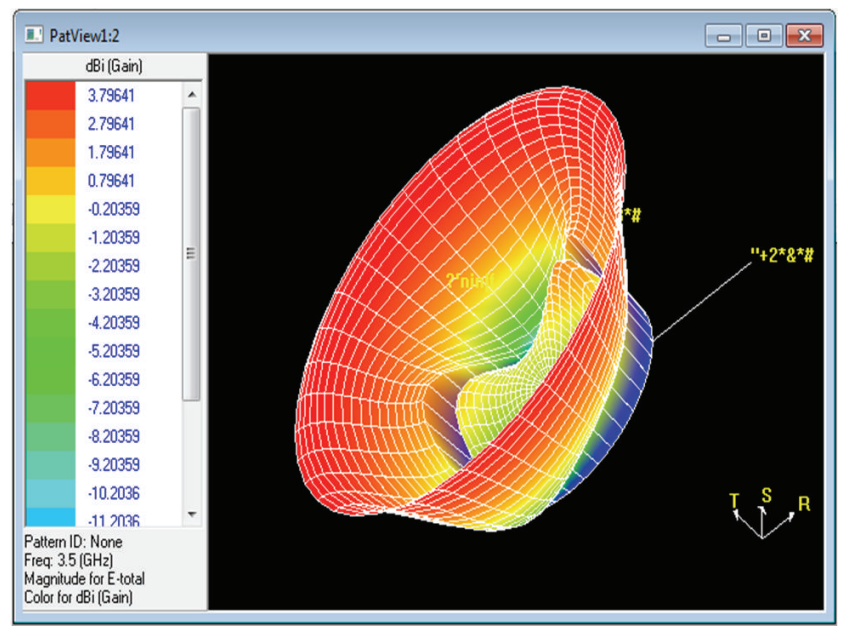

FIGURE 11: 3D radiation pattern.

\section{Conclusion}

In this paper, we presented the design of the backfire rectangular patch antenna for bandwidth enhancement covering the $3 \mathrm{GHz}-8 \mathrm{GHz}$ frequency spectrum. It has been shown that this design of the back fire rectangular patch antenna produces a bandwidth of approximately $52.8 \%$ with a stable radiation pattern within the frequency range. The design antenna exhibits a good impedance matching of approximately $50 \mathrm{Ohms}$ at the center frequency. This antenna can be easily fabricated on FR4 substrate material due to its small size and thickness. The simple coaxial feeding technique used for the design of this antenna makes its antenna a good choice in many communication systems.

\section{Conflict of Interests}

The authors declare that there is no conflict of interests regarding the publication of this paper.

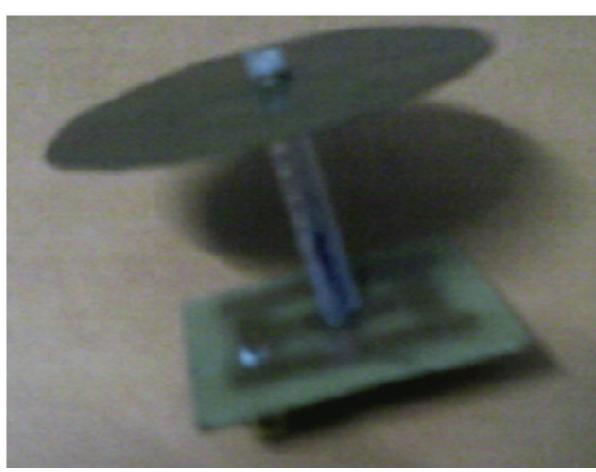

FIGURE 12: Side view of proposed antenna.

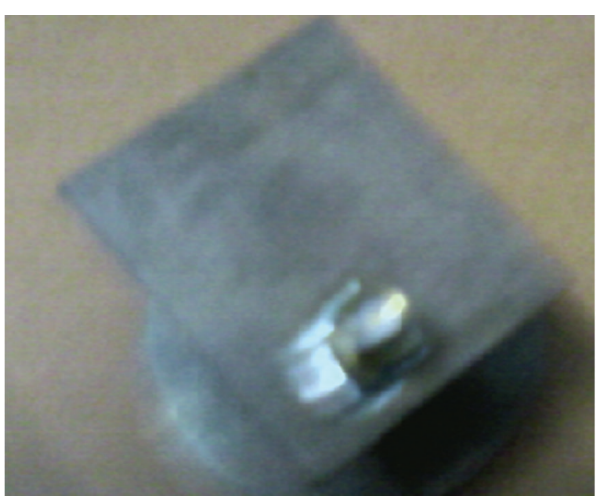

FIGURE 13: Ground plane of proposed antenna.

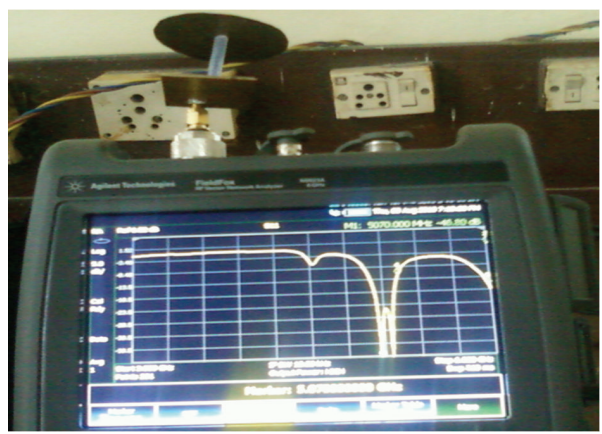

FIgURE 14: Hardware testing on Agilent N9923A.

\section{Acknowledgment}

The authors would like to express their thanks to the anonymous referees for their helpful comments and suggestions which improve the presentation of the paper.

\section{References}

[1] G. S. Kirov and H. D. Hristov, "Study of backfire antennas," Journal of Microwaves, Optoelectronics and Electromagnetic Applications, vol. 10, no. 1, pp. 1-12, 2011.

[2] C. A. Balanis, Antenna Theory, John Wiley \& Sons, 3rd edition, 2005. 
[3] S. Qu, J. Li, Q. Xue, C. H. Chan, and S. Li, "Wideband and unidirectional cavity-backed folded triangular bowtie antenna," IEEE Transactions on Antennas and Propagation, vol. 57, no. 4, pp. 1259-1263, 2009.

[4] M. J. Asad, M. Zafrullah, M. K. Islam, and M. Amin, "Development of short backfire antenna fed by H-shaped excitation structures," in Proceedings of the 17th International Conference on Telecommunications (ICT '10), pp. 449-454, April 2010.

[5] G. S. Kirov, "Design of short backfire antennas," IEEE Antennas and Propagation Magazine, vol. 51, no. 6, pp. 110-120, 2009.

[6] R. Li, D. C. Thompson, J. Papapolymerou, J. Laskar, and M. M. Tentzeris, "A circularly polarized short backfire antenna excited by an unbalance-fed cross aperture," IEEE Transactions on Antennas and Propagation, vol. 54, no. 3, pp. 852-859, 2006.

[7] R. Li, D. Thompson, J. Papapolymerou, J. Laskar, and M. M. Tentzeris, "A new excitation technique for wide-band short backfire antennas," IEEE Transactions on Antennas and Propagation, vol. 53, no. 7, pp. 2313-2320, 2005.

[8] G. S. Kirov, G. T. Chervenkov, and C. D. Kalchev, "Aperture coupled microstrip short backfire antenna," Journal of Electrical Engineering, vol. 63, no. 2, pp. 75-80, 2012. 

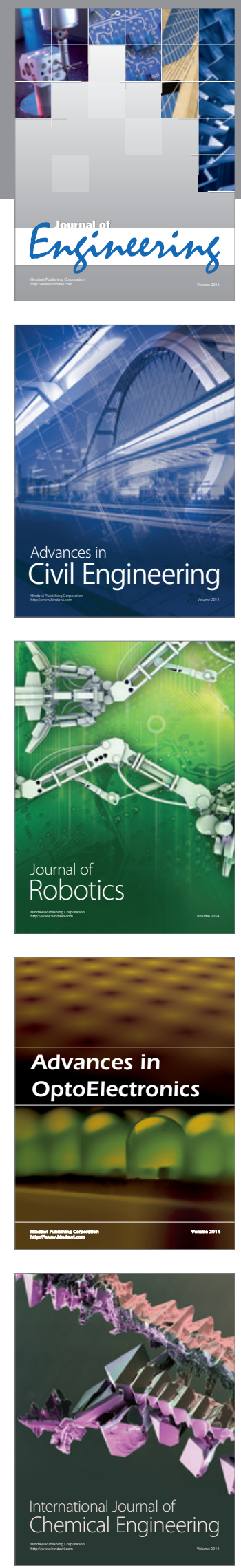

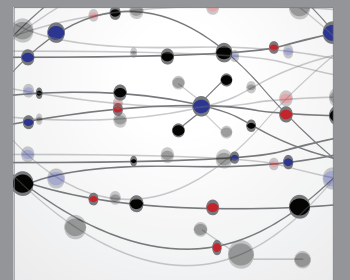

The Scientific World Journal
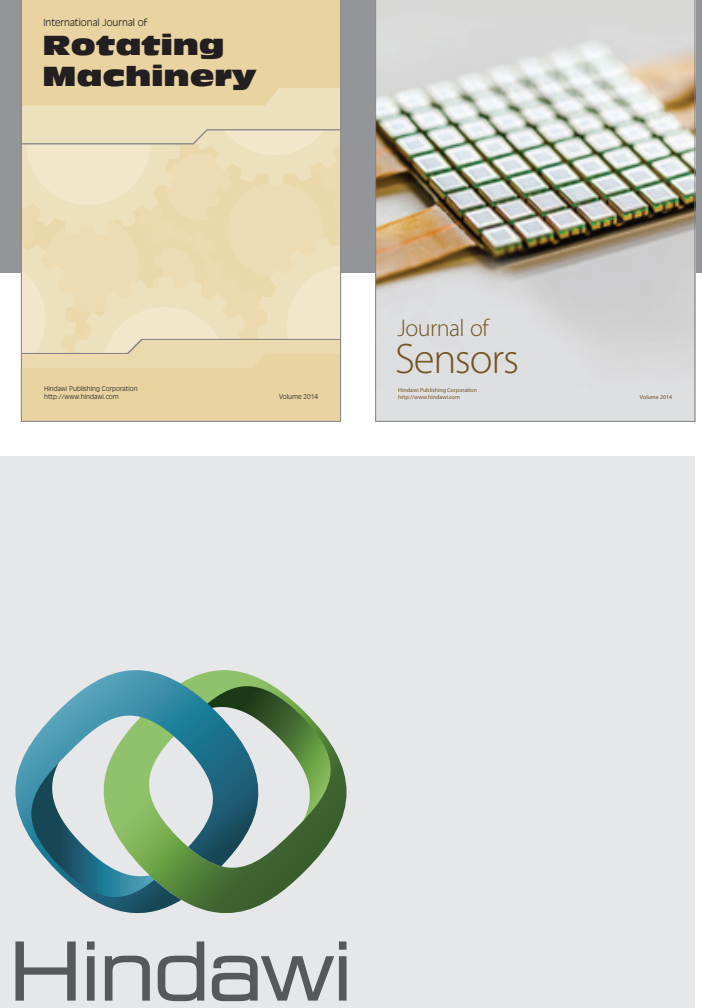

Submit your manuscripts at http://www.hindawi.com
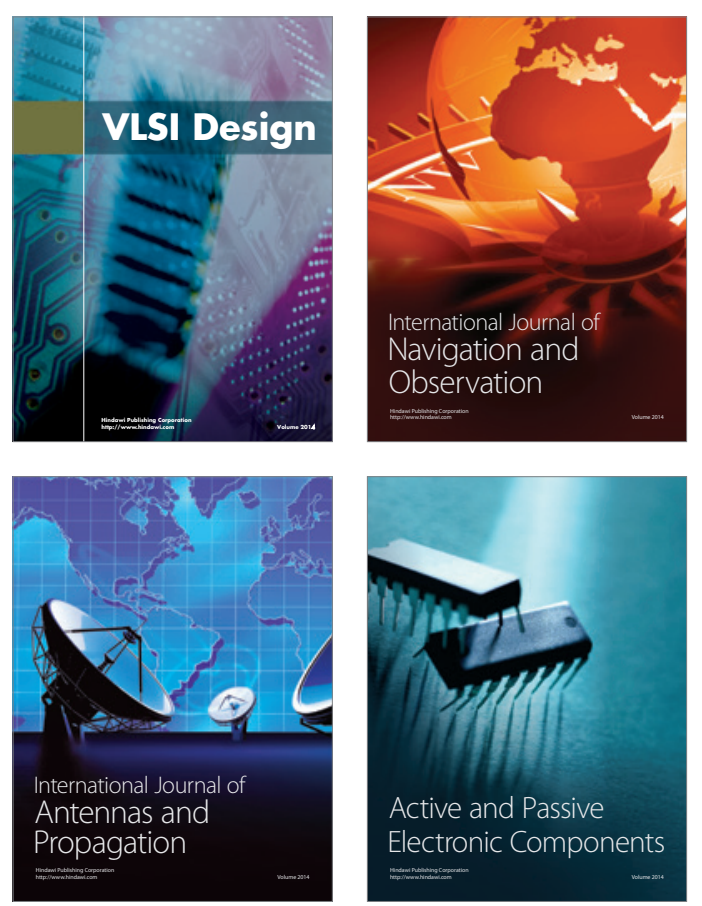
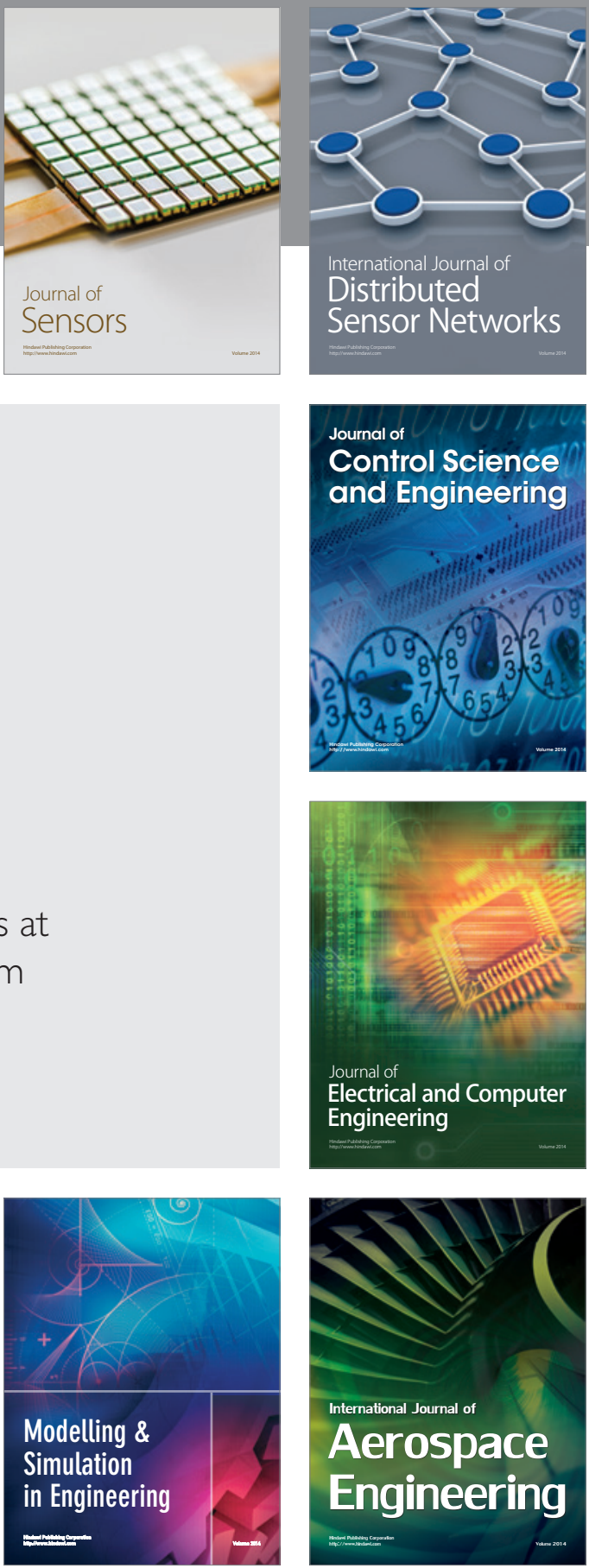

Journal of

Control Science

and Engineering
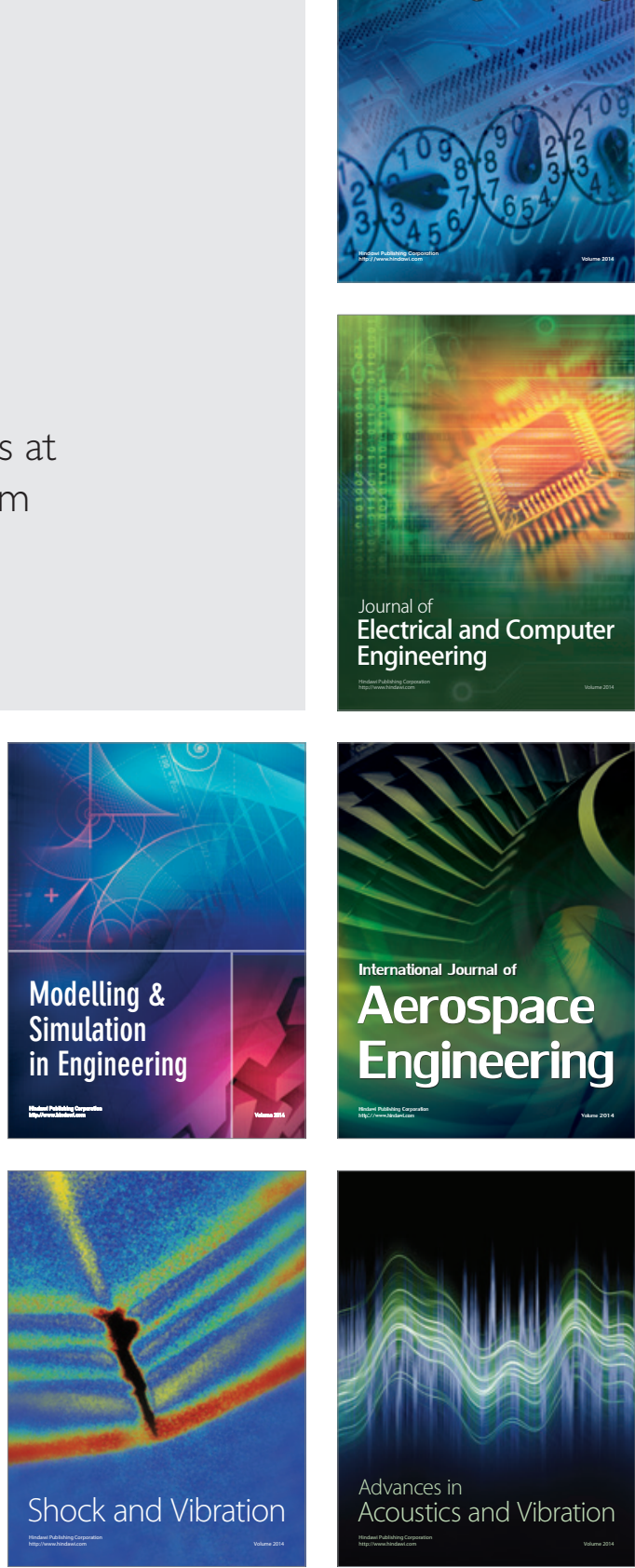